\title{
PHENOLIC COMPOUNDS PROFILING AND ANTIOXIDANT CAPACITY OF FIVE ECOTYPES OF TUNISIAN JERUSALEM ARTICHOKE
}

\author{
Wafa Saidi ${ }^{1,2,}$ Fatma Kalleli ${ }^{1,3^{*}}$, Hayet Beltayef ${ }^{2,5}$ and Mahmoud M'Hamdi ${ }^{1,4}$ \\ ${ }^{1}$ Department of Horticultural Sciences and Vegetable Crops, High Institute of Agronomy of Chott Mariem, \\ University of Sousse, 4042 Sousse, Tunisia; \\ ${ }^{2}$ Research laboratory: Support for sustainable agricultural productivity in the North West region,EL KEF Higher \\ School of Agriculture,7119,EL KEF,Tunisia \\ ${ }^{3}$ LR13AGR02 Improvement and Integrated Development of Animal Productivity and Food Resources, University of \\ Carthage, Mateur Higher School of Agriculture, 7030, Mateur, Tunisia; \\ ${ }^{4}$ Horticultural Science Laboratory, National Agronomic Institute of Tunisia. University of Carthage, Tunisia. \\ ${ }^{5}$ Faculé des Sciences de Bizerte, University of Carthage, Zarzouna, Tunisia \\ https://doi.org/10.35410/IJAEB.2021.5687
}

\begin{abstract}
In the present investigation, acetonic extracts from tubers of Tunisian Helianthus Tuberosus L. were assayed for their chemical composition and antioxidant activity. The phenolic composition of the acetonic extracts was determined by reverse phase high performance liquid chromatography (RP-HPLC). The phenolic composition of all extracts was characterized by its richness in trans-cinnamic acid, flavonose, carnosic acid and warfarin. Total phenolic content (TPC) measured by the Folin-Ciocalteu assay in Jerusalem artichoke extracts of five ecotypes ranged from $502.36 \mu \mathrm{mol} / 100 \mathrm{~g} \mathrm{FW}$ (ecotype 2) to $2640.15 \mu \mathrm{mol} / 100 \mathrm{~g} \mathrm{FW}$ (ecotype4). A positive correlation between total phenols contents and antioxidant activity was recorded for all ecotypes with the extract of ecotype 4 showed highest antioxidant activity in DPPH radical scavenging assay (3.62 $\mathrm{mol} / \mathrm{g} \mathrm{MF}$ ). Our findings demonstrate that the acetonic extracts of Helianthus Tuberosus L. possess significant antioxidant activity and may be suggested as a new potential source of natural antioxidant.
\end{abstract}

Keywords: Helianthus Tuberosus, Jerusalem artichoke, Tunisia, phenolic composition, antioxidant activity.

\section{INTRODUCTION}

Currently the concept of functional food is a new quality orientation. It is the result of our society evolution toward a power supply which also responds well to the nutritional requirements or organoleptic characteristics, but also possess a beneficial potential for health. A food is said "functional" if it has effects on one or several functions targets of the body, beyond its strength's nutrients, improving the state of well-being or the health status of individuals, or reducing the risk of a disease (Roberfroid, 2005). Based on this definition and by its specific composition in various nutrients, the Jerusalem artichoke belongs today to this class of foods.

Jerusalem artichoke (Helianthus tuberosus L.) is a species of the Asteraceae family, genus Helianthus, known for the remarkable genetic variability of its clones and genotypes (Puttha et al., 2013). Helianthus tuberosus L.(Asteraceae), a perennial plant, is a sunflower species originating from the Ohio and Mississippi River valleys in the United states that has been introduced and become naturalized as an economic crop worldwide in temperate areas. 
Vol. 06, No. 06; 2021

ISSN: $2456-8643$

Helianthus tuberosus has a 5-10 tall stems, large leaves, bright yellow sunflower, and fleshy tubers resembling those of potatoes.

In Mediterranean regions it spontaneously grows virtually everywhere and does not require any kind of fertilizer or organic matter and should not be subjected to pesticides. Its rapid and vigorous growth allows good natural control against weeds, which hardly exceed the plant (Rosati, 2010).

The tubers of $\mathrm{H}$. tuberosus have been utilized not only as a food but also as a raw material in the bioethanol industry for its high content of inulin, a fructan that can be easily hydrolyzed. (Annalisa et al.,2010). It is indeed long been recognized that the Jerusalem artichoke presents a profile very interesting to compounds beneficial to human health. The tubers of Jerusalem artichoke can be used for human nutrition, view its low-calorie content and the presence of inulin which also has positive effects on health (Roberfroid, 2005).

Helianthus tuberosus is mainly cultivated for use as green or brackish fodder as crops in marginal areas, especially in relation to hardiness and low production costs (Shanzhao et al., 2013) and for the production of sugars and soluble fiber. The plant is futhermore an excellent resource for bioenergy production, such as methane, bioethanol, anaerobic digestion and biogas from pyrolysis (Kim and Kim, 2014). Helianthus tuberosus can be appreciated not only as a biomass crop resource but also for its nutritional and medical qualities as an accessible source of protein and essential amino acids (Cieślik et al., 2011), minerals (Terzić et al., 2012) and a number of functional ingredients such as inulin, oligofructose and fructose. Besides, it has both nutritional and functional attributes, particularly beneficial for individuals with type 2 diabetes and obesity (Yang et al., 2015).As the majority of the plants, Jerusalem artichokes contain antioxidant compounds that include vitamins, carotenoids and flavonoids (Vadakkemuriyil et al., 2013). In recent years many studies have shown that free radicals are the main cause of degenerative diseases, many phenols have a biological protection against these radicals (Shao et al., 2008). The composition of these bioactive compounds can be affected by internal and external factors. Such modification of this composition, under the influence of one factor or another, could lead to the modification of the characteristic biological properties of plant (Kalleli et al., 2019). Thus, the objective of this investigation was to determine the phytochemical and antioxidant potential of Helianthus tuberosus tubers from Tunisian regions in order to find the ideal origin producing more bioactive compounds.

\section{MATERIEL AND METHODS}

Plant Materiel

The plant material is a collection of different stations of the Kef (Tunisia) region that belong to the same bioclimatic floor.

\section{Extract preparation}

The extraction was carried out using the method developed by Fattouch et al. (2008) with minor modifications. Each $1 \mathrm{~g}$ of tuber was mixed with $10 \mathrm{ml}$ of cold aqueous acetone $70 \%$. The homogenate was sonicated for $10 \mathrm{~min}$ and then centrifuged at $8000 \mathrm{~g}$ for $15 \mathrm{~min}$ at room temperature. Supernatants were concentrated using a rotary evaporator $\left(40^{\circ} \mathrm{C}\right)$ under vacuum to a 
Vol. 06, No. 06; 2021

ISSN: $2456-8643$

final volume of $3 \mathrm{ml}$. To prevent oxidation of the polyphenols, extraction was achieved rapidly, and the final extract solutions were stored at $-20^{\circ} \mathrm{C}$ until analyzed.

\section{Determination of total phenolic content}

The total phenol content (TPC) was measured through spectrophotometric determination with the Folin-Ciocalteu method as reported by Tuberoso et al. (2007). The absorbance was read at $725 \mathrm{~nm}$ on a10 mm quartz cuvette using a Varian Cary spectrophotometer against a blank. The TPC results, expressed as milligrams of gallic acid equivalent (GAE) per 100g of fresh weight (FW) were obtained using a calibration curve of a freshly prepared gallic acid standard solution (10-200mg /1). All of the measurements were taken in triplicate, and means and standard deviation value were calculated.

\section{Antiradical activity (DPPH Test)}

This essay is based on the ability of the antioxidant to scavenge the radical cation DPPH. The method described by Tuberoso et al,(2007) was used starting from 50 $\mu$ Lof water- diluted extract. The simple was mixed with $2 \mathrm{ml}$ of DPPH $0.04 \mathrm{Mm}$ in methanol. Antiradical activity was measured as the relative decrease in absorbance at $517 \mathrm{~nm}$ as the reaction between DPPH and antioxidant. Reading was carried out with a Cary spectrophotometer. A calibration curve in the rang 0.02-0.8 Mm was used for Trolox, and data were expressed as Trolox equivalent antioxidant capacity (TEAC, $\mu \mathrm{mol} / \mathrm{g}$ fw).

\section{Identification of phenolic compounds by HPLC}

The HPLC used throughout our experiment is Hypersil ODS-C18 $(5 \mu \mathrm{m} ; 4,6 \mathrm{~mm} * 250 \mathrm{~mm})$. The mobile phase consists of solvent $\mathrm{B}$ : acetonitrile and solvent $\mathrm{C}$ : which contains water at $0,2 \%$ formic acid. The injection volume used is $50 \mu \mathrm{l}$ and the UV spectrum was $280 \mathrm{~nm}$.

\section{Statistical Analysis}

All testes and analyses were run in triplicate and averaged. Quantitative presented data are means \pm standard deviation (SD). One-way analysis of variance (ANOVA) with Dunnett's posttest was performed using Graph Pad Prism version 4.00 for windows. Difference of $\mathrm{P}<0.05$ were considered significant.

\section{RESULTS}

\section{Total phenolic content}

The total phenol contents of Jerusalem artichoke extracts from five provenances are shown in Figure 1. There were significant differences $(\mathrm{p}<0.05)$ in total phenolic contents between these different provenances varying from 502.36 to $2640.15 \mu$ soft / 100g FW. The highest content of total phenolic was found in the ecotype $4(2640.15 \mu$ soft / 100g FW). 


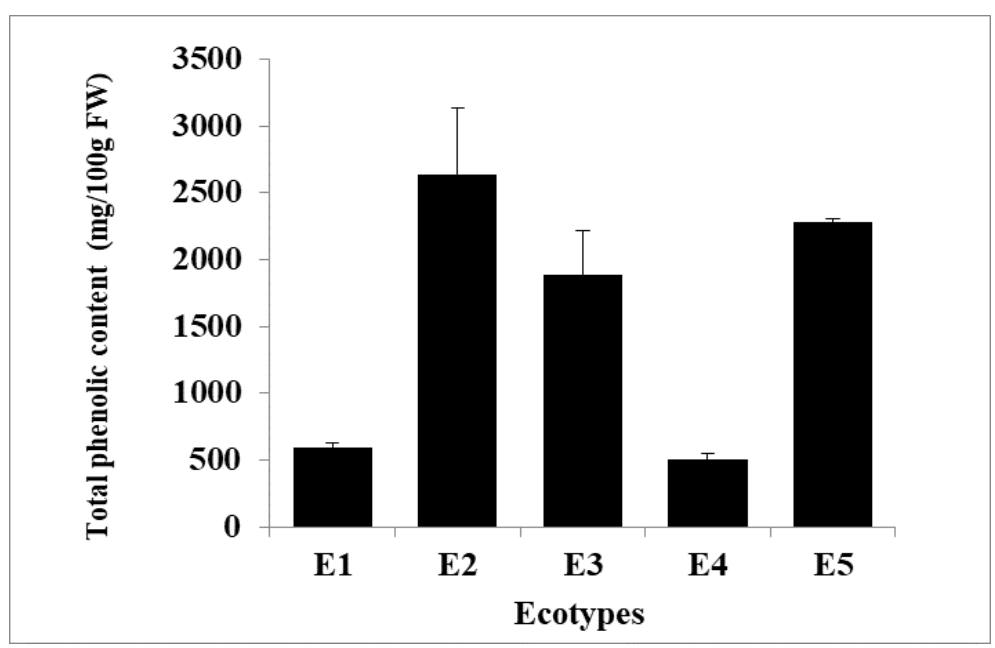

Figure 1. Total phenolic content of Jerusalem artichoke ecotype.

Values are mean of three replicates.

Antioxidant activity (Capacity of inhibition of free radical DPPH)

Antioxidant activity of the extracts of five Jerusalem artichokes ecotypes are shown in figure 2. Results showed that Jerusalem artichokes extracts from the different provenances had different Capacity of inhibition of free radical DPPH. Ecotype 4, is characterized by the highest antioxidant activity TEAC $=3,62 \mu \mathrm{mol} / \mathrm{g}$ FW. Ecotypes $1,2,3$ and 5 recorded respectively $(2,32)$; $(1,50) ;(1,55)$ and $(2,79 \mu \mathrm{mol} / \mathrm{g} \mathrm{FW})$. Indeed, a positive correlation between the total phenols content and the antioxidant activity was recorded for all the ecotypes.

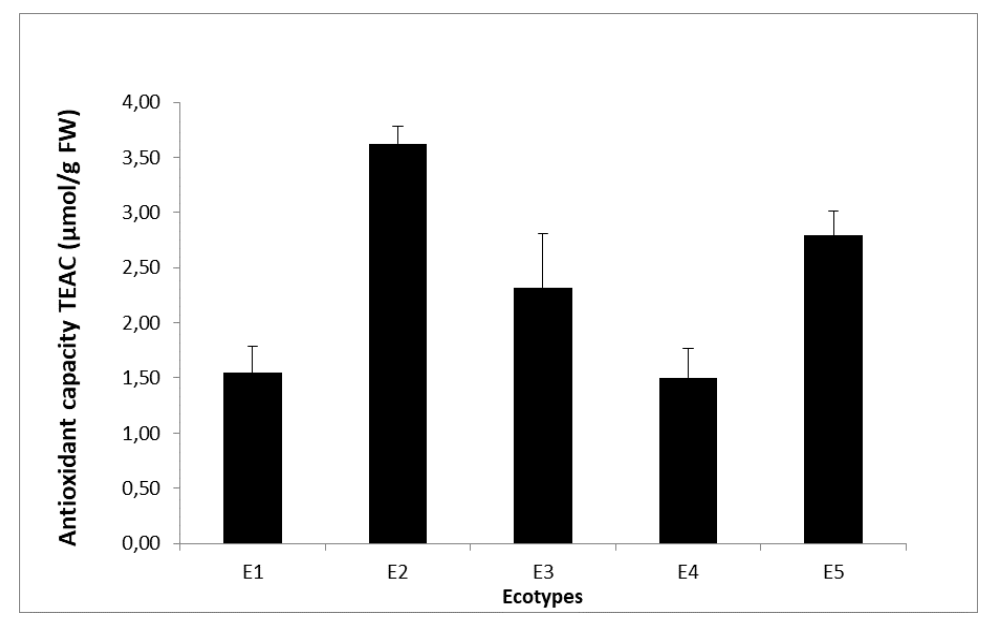

Figure 2. Antioxidant capacity of different phenolic extracts of five Jerusalem artichoke ecotypes (DPPH free radical inhibition capacity). Values are mean of three replicates.

Separation and identification of the phenolic compounds by HPLC

The results of phenolic identification compounds by HPLC showed a heterogeneity between the various ecotypes in regard to this composition. Indeed, thirteen made up was identified by 
Vol. 06, No. 06; 2021

ISSN: $2456-8643$

comparison of UV and time of retention with compounds of reference. There are some peaks which remain to be identified by more precise means. Identified compounds are: Flavonol, chalcone, carnosoic acid, flavonose, genestein, uteolin, warfarin, flavone, gallic acid, 5,7dihydroxyflavone, naringenin 7-O-glucoside, trans cinnamic.

Ecotype 4 has the most diverse phenol composition with the majority of phenolic compounds, which is correlated with its polyphenol content and antioxidant activity relative to other ecotypes. Carnosoic acid is the common phenolic compound of all ecotypes with a higher amount based on peak air (221) for ecotype 5 .

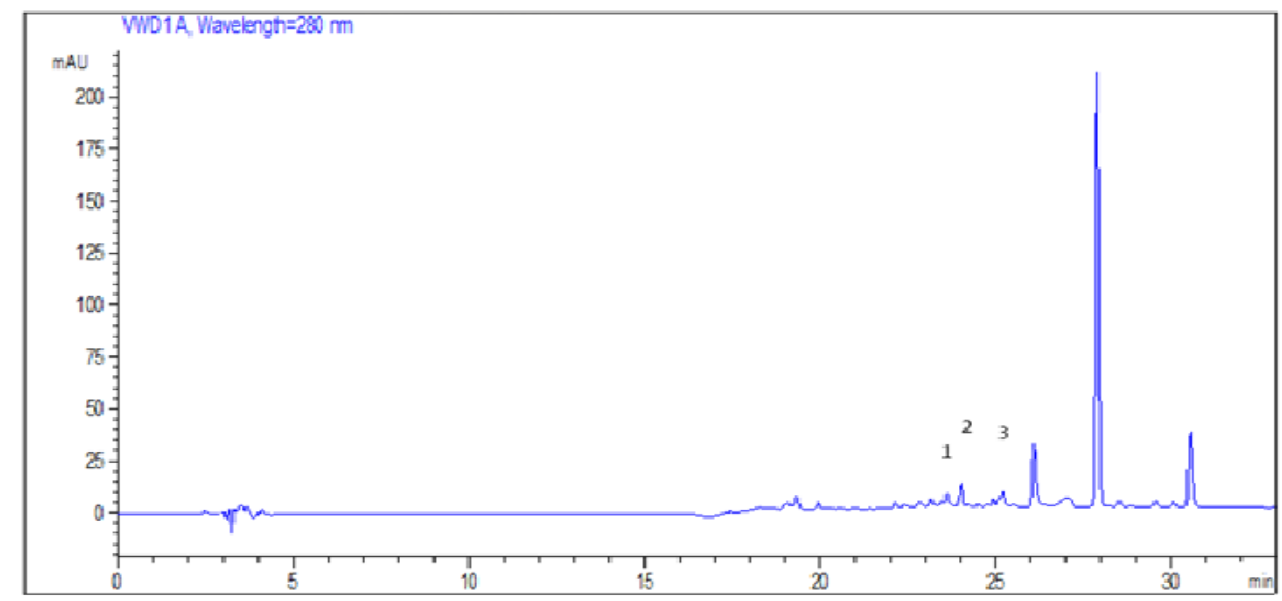

Figure 3. Chromatogram of Jerusalem artichoke tuber phenolic extract from ecotype 1: flavonol (1), Chalcone (2) and carnosic acid (3)

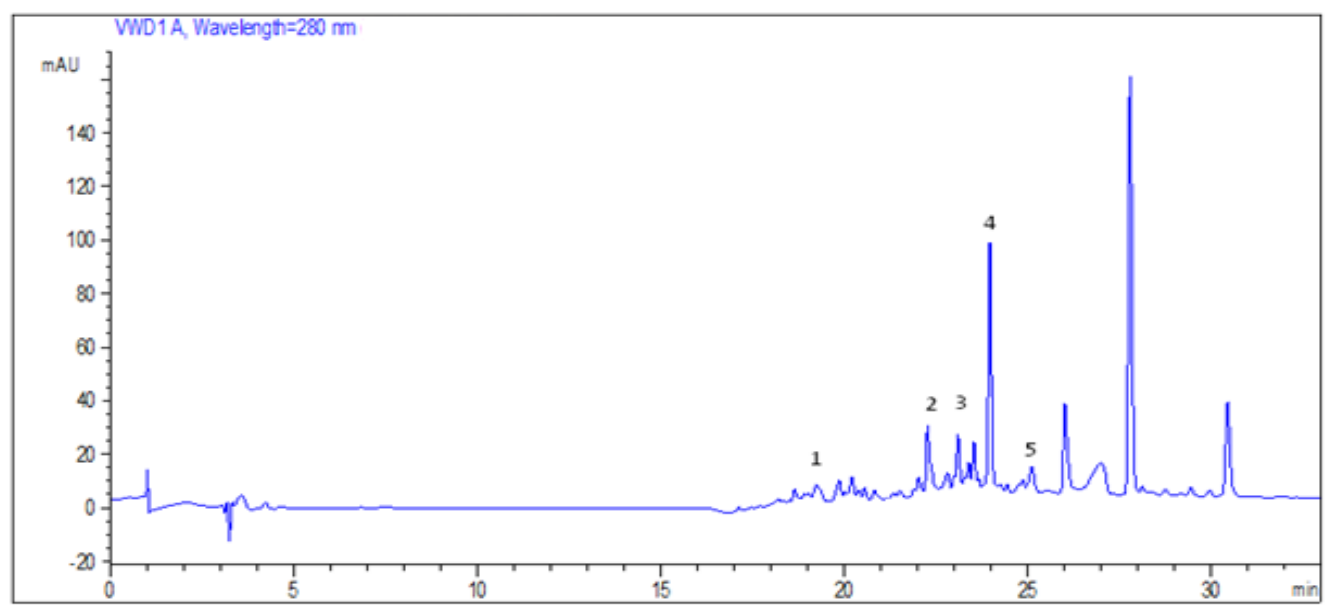

Figure 4. Chromatogram of Jerusalem artichoke tuber phenolic extract from ecotype 2: flavonol (1), Chalcone (2) and carnosic acid (3) 
Vol. 06, No. 06; 2021

ISSN: 2456-8643

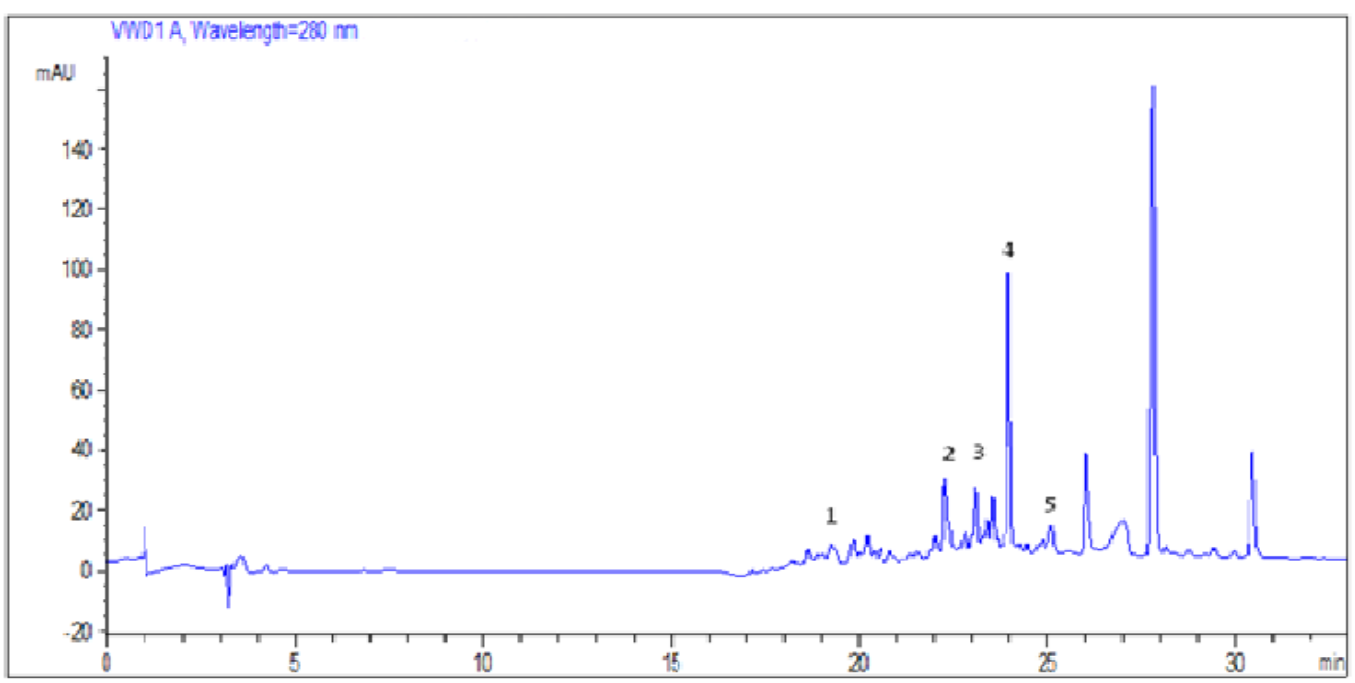

Figure 5. Chromatogram of Jerusalem artichoke tuber phenolic extract from ecotype 3: Uteolin (1), Warfarin (2), 5,7dihydroxyflavone (3), flavonose (4) and carnosic acid (5)

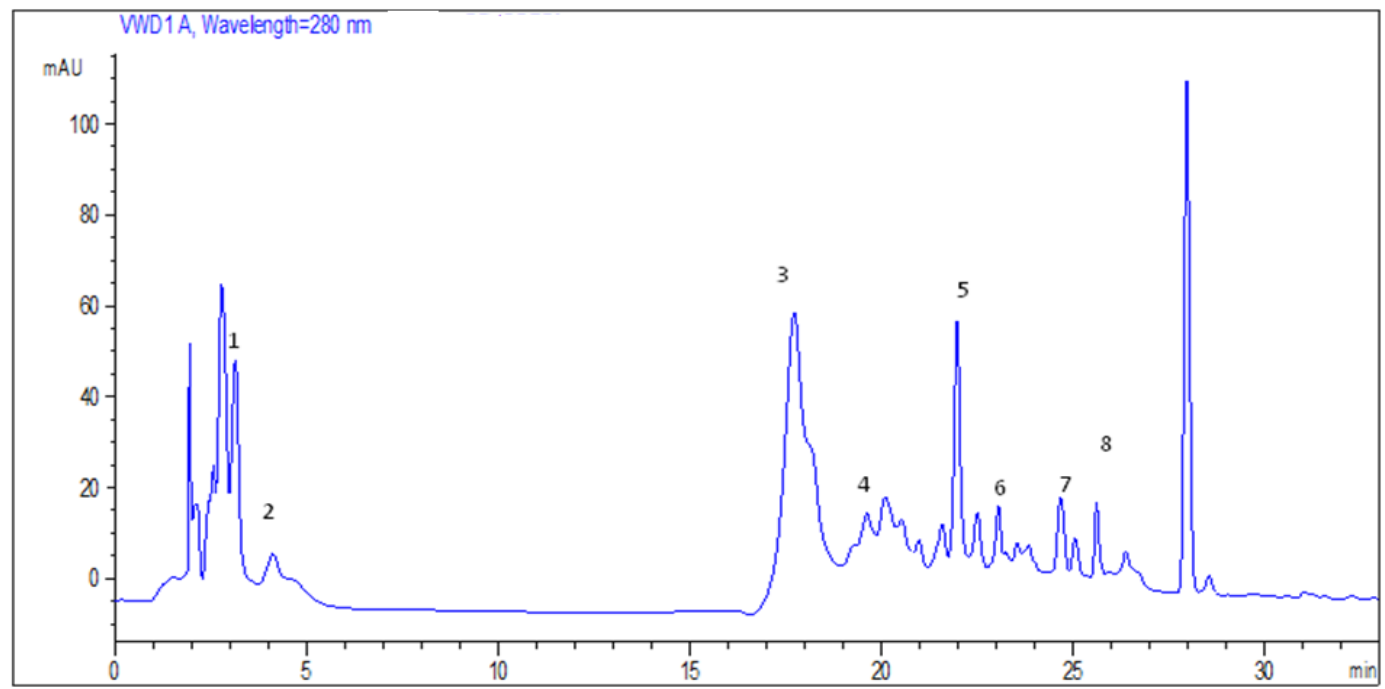

Figure 6. Chromatogram of Jerusalem artichoke tuber phenolic extract from ecotype 4: gallic acid (1), procatechic acid (2), naringenin-7-O-glucoside (3), trans cinnamic acid (4), Warfarin (5) , 5,7dihydroxyflavone (6), chalcone (7) and carnosic acid (8). 


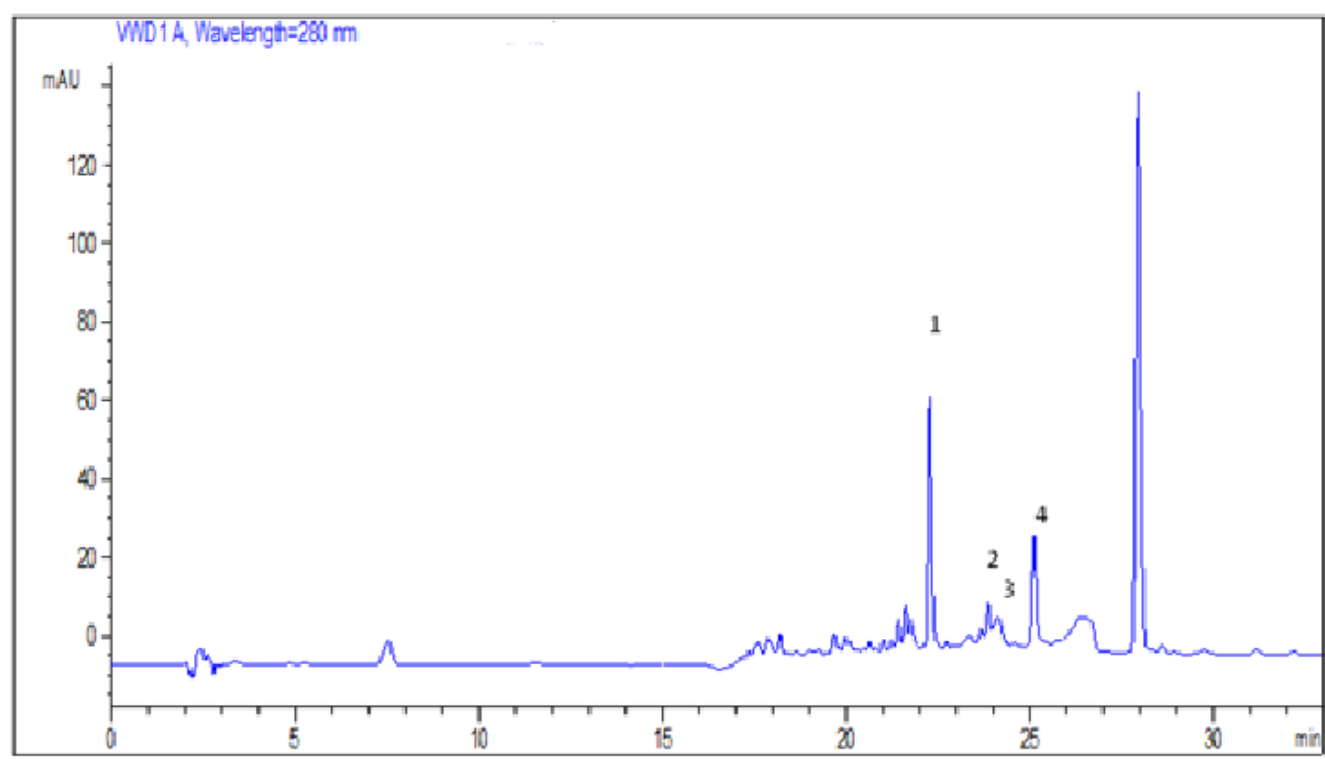

Figure 7. Chromatogram of Jerusalem artichoke tuber phenolic extract from ecotype 5: warfarin (1), flavonose (2), chalcone (3) and carnosic acid.

Table1. The main phenolic compounds in the tubers extracts of Jerusalem artichoke and their availability in the different ecotypes.

\begin{tabular}{|c|c|c|c|c|c|}
\hline Ecotypes & E3 & E4 & E1 & E2 & E5 \\
\hline Phenolic compounds & & & & & \\
\hline Flavonol & - & - & + & - & - \\
\hline Chalcone & - & + & + & + & + \\
\hline Carnosoic acid & + & + & + & + & + \\
\hline Flavonose & + & - & - & + & + \\
\hline Genestein & - & - & - & + & - \\
\hline Uteolin & + & - & - & - & - \\
\hline Warfarin & + & + & - & - & + \\
\hline Flavone & + & - & - & + & - \\
\hline Gallic acid & - & + & - & - & - \\
\hline
\end{tabular}




\begin{tabular}{|llllll|}
\hline Naringenin-7-0-glucoside & - & + & - & - & - \\
\hline
\end{tabular}

(+) Present ;(-) Absent

\section{DISCUSSION}

Since about fifteen years, the search for natural antioxydants or extracts with antioxidant capacity caused much interest. Thus a whole series of plants had reviewed, and in particular the spices. Many compounds responsible for the antioxydant capacity were identified. They are especially phenols and polyphenols

Concerning the antioxydant capacity of Jerusalem artichokes, our results were based on the inhibition capacity of free radical DPPH. Indeed, the estimate of inhibition capacity of free radical DPPH by extract phenolic from Jerusalem artichokes is a suitable model of the antioxydant capacity estimation (Sanchez-Moreno, 2002). The antioxydant activities of the extracts of plant are closely dependent has their polyphenol contents (Ratheeet et al., 2007). It explains the important correlation between the quantity out of polyphenols and the antioxydant capacity of the various extracts, in our study $\left(\mathrm{R}^{2}=0.96037\right)$. These results agree with those of Yuan et al. (2012) and Fujia et al. (2013). The antioxidant potency and the content of the most important total phenols have been recorded in ecotype 4, but these remain lower than those recorded in other research. Indeed, Naczk et al. (2003) showed that Jerusalem artichoke leaves are richer in polyphenols and have a higher antioxidant value than tubers. Yuan et al. (2012) reported very high antioxidant potency in leaves of Jerusalem artichokes $(304.74 \mathrm{mg} / \mathrm{ml})$ with high polyphenols content $(266.69 \mathrm{mg} / \mathrm{g})$. The identification of phenolic compounds by HPLC of the tubers extracts has shown us that the composition in phenols is different from that of the leaves reported by (Lee et al., 2010; Peng et al., 2000; Tolonen et al., 2002; Yuan et al., 2012).Yuan et al. (2012) identified six phenolic compounds in Helianthus tuberosus leaf extracts: 3- O-caffeoylquinic acid (3-CQA), caffeic acid (2), 3,5-dicaffeoylquinic acid (3,5-DiCQA, 3), 1,5- dicaffeoylquinic acid (1,5-DiCQA, 4), 4,5-dicaffeoylquinic acid (4,5- DiCQA, 5) and 3,5- 
Vol. 06, No. 06; 2021

ISSN: $2456-8643$

dicaffeoylquinic acid ether. As for our results for tuber extracts, ten main compounds were identified with heterogeneity between the ecotypes and which are totally different to the ecotypes (Table1).

\section{CONCLUSIONS}

This study revealed a significant variation in the biochemical composition of Tunisian Jerusalem artichoke ecotypes. Ecotype 4 has the most diverse phenol composition in which most of the phenolic compounds are found, which correlates with its polyphenol content and its antioxidant capacity compared to other ecotypes. The presence of carnosic acid in the extracts of Jerusalem artichoke tubers can put the species as an object of industrial development to enhance its composition especially that despite the diversity of plants that have an excellent ability to inhibit oxidative reactions, only rosemary has been the subject of industrial development. In addition, the presence of warfarin or coumaphene in both E3 and E4 ecotypes suggests the use of extracts of both ecotypes as bio-insecticides and also in pharmaceutical uses, although coumaphenebased drugs have an anticoagulant effect.

\section{REFERENCES}

Annalisa, T., Bagni, N., Ferri, M., Khomutouv,A., Marques, M. P., Fiuza,S.,Simonian,A. and Donatella ,S.F.(2010).Helianthus tuberosus and polyamine research past and recent application for a classic growth model. Plant physiology and biochemistry,496-505

Fattouch, S., Caboni, P., Coroneo, V. Tuberoso, C.I.G. Angioni, A. Dessi, S. Marzouki, N. Cabras, P. (2008). Comparative analysis of polyphenolic profiles and antioxidant and antimicrobial activities of Tunisian pome fruit pulp and peel aqueous acetone extracts. Journal of Agricultural and Food Chemistry. 56, 1084-1090.

Fujia.C, Xiaohua.L, Mengni.Y, Zhaopu.L.and Ling.L. (2013). Phenolics and antifungal activities analysis in industrial crop Jerusalem artichoke (Helianthus tuberosusL.) leaves. Industrial Crops and Products, 47: 339-345.

Lee, E. J., Kim, J. S., Kim, H. P., Lee, J. H., and Kang, S. S. (2010). Phenolic constituents from the flower buds of Lonicera japonica and their 5-lipoxygenase inhibitory activities. Food Chemistry, 120: 134-139.

Naczk, M., Amarowicz, R., Zadernowski, R., Pegg, R., and Shahidi, F. (2003). Antioxidant activity of crude phenolic extracts from wild blueberry leaves. Polish Journal of Food and Nutrition Sciences, 53: 166-169.

Rathee, J. S., Hassarajani, S. A., and Chattopadhyay, S. (2007). Antioxidant activity of Nyctanthes arbor-tristis leaf extract. Food Chemistry. 103, 1350-1357.

Roberfroid, M. (2005). Inulin-Type Fructans: Functional Food Ingredient.CRC Series in Modern Nutrition, CRC Press, Boca Raton, FL.

Sánchez-Moreno, C. (2002). Review: Methods used to evaluate the free radical scavenging activity in foods and biological systems. Food Science and Technology International, 8(3): 121137. 
Vol. 06, No. 06; 2021

ISSN: $2456-8643$

Shao, H.B., Chu, L.Y., Lu, Z.H., Kang, C.M. (2008). Primary antioxidant free radical. Scavenging and redox signaling pathways in higher plant cells. International Journal of Biological Sciences; 4: 8-14.

Tuberoso, G.Carlo ,Adamkoowalczyk.Erica .Z and Paolo .C(2007).Determination of antioxidant compounds and antioxidant activity in commercial oilseeds for food use Food Chemistry ;4: 1494-1501

Peng, L. Y., Mei, S. X., Jiang, B., Zhou, H., and Sun, H. D. (2000). Constituents from Lonicera japonica. Fitoterapia,71: 713-715.

Tolonen, A., Joutsamo, T., Mattlla,S., Kämäräinen, T.,and Jalonen, J. (2002).Identification of isomeric dicaffeoylquinic acids from Eleutherococcus senticosus using HPLC-ESI/TOF/MS and 1H-NMR methods. Phytochemical Analysis, 13: 316-328.

Vadakkemuriyil Divya Nair, Rajaram Panneerselvam, Ragupathi Gopi, Shao, H.B. (2013). Elicitation of pharmacologically active phenolic compounds from Rauvolfia serpentina Benth. Ex. Kurtz. Indien Crop Production, 45: 406-415

Yuan, X., Gao, M., Xiao, H., Tan, C., Du, Y., (2012). Free radical scavenging activities and bioactive substances of Jerusalem artichoke (Helianthus tuberosus L.) leaves. Food Chem, 133:10-14.

Rosati, A., 2010. Coltivate il topinambur, il sapore dei suoi tuberi ricorda quello del carciofo. Vita Camp. 10, 23-25 〈http://www.informatoreagrario.it/bdo/ RVC101986.asp〉.

Puttha, R., Jogloy,S., Surihan, B., Puangsomlee Wangsomnuk,P., Kesmala,T. and Patanothai,A. 2013. Variations in morphological and agronomic traits among Jerusalem artichoke (Helianthus tuberosus L.) accessions. Genetic Resources and Crop Evolution volume 60, pages731-746.

Kalleli F, Bettaieb Rebey I, Wannes WA, et al. Chemical composition and antioxidant potential of essential oil and methanol extract from Tunisian and French fennel (Foeniculum vulgare Mill.) seeds. J Food Biochem. 2019;e12935. https://doi.org/10.1111/jfbc.12935.

Shanzhao, J., Ling, L., Zhaopu, L., Xiaohua, L., Hongbo, S., Jiayao, C., 2013. Characterization of marine PSEUDOMONAS pp. antagonist towards three tuber-rotting fungi from Jerusalem artichoke, a new industrial crop. Ind. Crops Prod. 43, 556-561.

Kim, S., Kim, C.H., 2014. Evaluation of whole Jerusalem artichoke (Helianthus tuberosus L.) for consolidated bioprocessing ethanol production. Renew. Energy 65, 83-91.

Cieślik, E., Gębusia, A., Florkiewicz, A., Mickowska, B., 2011. The content of protein and of amino acids in Jerusalem artichoke tubers (HELIANTHUS tuberosus l.) of red variety Rote Zonenkugel. Acta Sci. Pol. Technol. Aliment. 10, 433-441.

Terzić, S., Atlagić, J., Maksimović, I., Zeremski, T., Zorić, M., Miklić, V., 2012. Genetic variability for concentrations of essential elements in tubers and leaves of Jerusalem artichoke (Helianthus tuberosus L.). Sci. Hortic. 136, 135-144.

Yang, L., He, Q.S., Corscadden, K., Udenigwe, C., 2015. The prospects of Jerusalem artichoke in functional food ingredients and bioenergy production. Biotechnol. Rep. (Amst.) $5,77-88$. 